\title{
Guidelines, process and ethics with the New Zealand Mental Health (compulsory assessment and treatment) Act: striking a balance Christopher Gale*1, Richard Mullen ${ }^{1}$ and Lily Shue ${ }^{2}$
}

\author{
Address: ${ }^{1}$ Department of Psychological Medicine, Dunedin School of Medicine, P O Box 913, Dunedin 9054, New Zealand and ${ }^{2}$ Department of \\ General Practice and Primary Health Care, School of Population Health, University of Auckland, Private Bag 92019, Auckland 1000, New Zealand \\ * Corresponding author
}

from WPA Thematic Conference. Coercive Treatment in Psychiatry: A Comprehensive Review

Dresden, Germany. 6-8 June 2007

Published: 19 December 2007

BMC Psychiatry 2007, 7(Suppl I):SI02 doi:10.1I86/I47I-244X-7-SI-SI02

This abstract is available from: http://www.biomedcentral.com/I47I-244X/7/SI/SI02

(C) 2007 Gale et al; licensee BioMed Central Ltd.

The New Zealand Mental Health (compulsory assessment and treatment) act [1] was amended to mandate the consultation of family and care-givers in every stage of civil committal. Although the use of committal has been seen by clinicians as an impediment to care [2] and clinicians continue to have concerns about the timing of discharge from the act [3], many people with serious mental illness have experienced the act as beneficial [4]. A recent review of the regulations has increased the length and detail of the reports clinicians have to provide to the court. This, combined with a clear directive that an advocate who is not part of the clinical care process must be present during the clinical interview to commence committal, may be causing a conflict between the provision of care in a timely manner when patients are at risk and complying with the requirements of the court.

\section{References}

I. Statutes of New Zealand no 140: Mental Health (Compulsory Assessment and Treatment) Amendment Act 1999.

2. Romans S, Dawson J, Mullen R, Gibbs A: How mental health clinicians view community treatment orders: a national New Zealand survey. Aust N ZJ Psychiatry 2004, 38:836-84I.

3. Mullen R, Dawson J, Gibbs A: Dilemmas for clinicians in use of community treatment orders. Int J Law Psychiatry in press.

4. Gibbs A, Dawson J, Mullen R: Community treatment orders for people with serious mental illness: a New Zealand study. $\mathrm{Br}$ J Soc Work 2006, 36: 1085-1 100. 